\title{
Changes in exercise capacity, muscle strength, and health-related quality of life in esophageal cancer patients undergoing esophagectomy
}

Takayuki Inoue ${ }^{1 \dagger}$, Satoru Ito ${ }^{1,2^{*+}}$, Masahiko Ando ${ }^{3}$, Motoki Nagaya ${ }^{1}$, Hiromichi Aso ${ }^{2}$, Yota Mizuno ${ }^{1}$, Keiko Hattori ${ }^{1}$, Hiroki Nakajima', Yoshihiro Nishida', Yukiko Niwa', Yasuhiro Kodera ${ }^{4}$, Masahiko Koike ${ }^{4}$ and Yoshinori Hasegawa ${ }^{2}$

\begin{abstract}
Background: Surgery for cancer of the thoracic esophagus is a challenging procedure associated with high morbidity and mortality. Perioperative rehabilitation has been introduced to promote early mobilization of the patients and to prevent postoperative pulmonary complications. The purpose of the present study was to characterize the preoperative functional exercise capacity, muscle strength, anxiety, depression, and health-related quality of life (QOL) in patients with esophageal cancer, and to evaluate the impact of radical esophagectomy on these parameters.
\end{abstract}

Methods: We performed a retrospective review of 34 consecutive patients with newly diagnosed resectable esophageal cancer who underwent esophagectomy followed by postoperative rehabilitation from January to December 2014. Patients were tested for 6-min walk distance (6MWD), knee-extensor muscle strength, hand grip strength, the Hospital Anxiety and Depression Scale (HADS), and the chronic obstructive pulmonary disease (COPD) assessment test (CAT) before and two weeks after the surgery. Before surgery, the pulmonary function test, and components of the MOS 36-item Short-Form Health Survey (SF-36) Questionnaire for general health were assessed.

Results: The mean age was $67.3 \pm 8.1$ years. The patients were predominantly male (76.4\%), had high rates of smoking history (91.2\%), and squamous cell carcinoma (97.1\%). The predicted value for forced expiratory volume in $1 \mathrm{~s}$ was $94.0 \pm 15.9 \%$, and 12 patients (35.3\%) had COPD. The clinical stage was 0-I in 12 patients, II in 4 patients, III in 16 patients, and IV in 2 patients. Thirty-one patients (91.2\%) underwent open surgery. At the baseline, components of the SF-36 scores significantly correlated with CAT and HADS scores, and the physical status was significantly poorer in patients with COPD than those without. Comparisons between the preoperative and postoperative values revealed significant decreases in 6MWD, hand grip strength, isometric knee extensor muscle strength, and a significant increase in CAT scores but not in HADS scores after surgery. In multiple regression analysis, decreases in 6MWD after the surgery significantly correlated with the preoperative physical component summary of SF-36.

Conclusions: Our results indicate that surgery remained detrimental to health outcomes at two weeks. Further research should investigate whether prehabilitation would improve the postoperative outcomes, QOL, and physical fitness.

Keywords: Esophagectomy, COPD assessment test, Health-related quality of life, Pulmonary rehabilitation, Six-minute walk test

\footnotetext{
* Correspondence: itori@med.nagoya-u.ac.jp

${ }^{\dagger}$ Equal contributors

'Department of Rehabilitation, Nagoya University School of Medicine,

Nagoya 466-8550, Japan

2Department of Respiratory Medicine, Nagoya University School of Medicine,

Nagoya 466-8550, Japan

Full list of author information is available at the end of the article
}

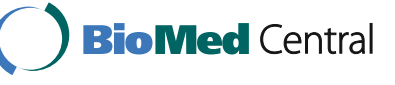

(c) The Author(s). 2016 Open Access This article is distributed under the terms of the Creative Commons Attribution 4.0 International License (http://creativecommons.org/licenses/by/4.0/), which permits unrestricted use, distribution, and reproduction in any medium, provided you give appropriate credit to the original author(s) and the source, provide a link to the Creative Commons license, and indicate if changes were made. The Creative Commons Public Domain Dedication waiver (http://creativecommons.org/publicdomain/zero/1.0/) applies to the data made available in this article, unless otherwise stated. 


\section{Background}

Esophagectomy is the standard therapy for patients with localized esophageal cancer, but it is a highly invasive procedure and associated with serious postoperative complications such as pulmonary complications, anastomotic leaks, and sepsis [1]. Major pulmonary complications after esophagectomy have been implicated in prolonged hospital stays and postoperative mortality [2, 3]. The preoperative health status is important because advanced age, preoperative chemoradiotherapy, and comorbidity of chronic obstructive pulmonary disease (COPD) are associated with the increased risk of postoperative complications and mortality [4, 5]. Moreover, it has been reported that a lack of preoperative physical activity and the loss of maximum oxygen uptake are risk factors for pulmonary or cardiopulmonary complications [6-8].

Perioperative rehabilitation has been expected to improve physical fitness, promote early mobilization, and reduce postoperative pulmonary complications in patients with esophageal cancer $[9,10]$. In order to manage the rehabilitation program, it is important to adequately assess the status of functional exercise capacity and health-related quality of life (QOL) before surgery. Moreover, esophagectomy itself worsens health-related QOL and physical fitness [11-13]. A prospective study by Reynolds et al. demonstrated that esophageal resection had a negative impact on health-related QOL as assessed by the 30-item European Organization for the Research and Treatment of Cancer (EORTC) QOL Core Questionnaires (QLQ) (EORTC QLQ-C30) [14] and esophageal cancer-specific EORTC QLQ (EORTC QLQOES24) [15] 3 months after surgery [12]. Moreover, Teoh et al. reported that esophagectomy was associated with worsened physical functioning and fatigue symptoms as assessed by EORTC QLQ-C30 and QLQ-OES24 up to 6 months after treatment [11]. Tatematsu et al. reported that 6MWD and knee-extensor muscle strength were significantly decreased approximately 3 weeks after esophagectomy [13]. However, the pre- and postoperative physical fitness, health-related QOL, psychological aspects, and their relationships have not been fully evaluated in patients with esophageal cancer who have undergone esophagectomy.

The purpose of the present study was to characterize the preoperative functional exercise capacity, muscle strength, anxiety, depression, and health-related QOL in patients with esophageal cancer, and to evaluate the impact of radical esophagectomy on these parameters 2 weeks after the surgery.

\section{Methods}

\section{Patients}

Records of 43 consecutive patients with esophageal cancer who underwent scheduled radical esophagectomy in the Department of Gastroenterological Surgery II, Nagoya University Hospital from January to December 2014 were retrospectively reviewed. Patients who underwent emergency surgery were not included. At our institution, perioperative pulmonary rehabilitation is routinely performed on patients who underwent esophagectomy. In addition, physical, mental, and QOL status are routinely assessed before and after surgery as the perioperative rehabilitation program according to previous reports and guidelines $[2,10,13,16-19]$. Patients are allowed to refuse the assessment if they do not wish. A flow chart describing the inclusion process is shown in Fig. 1. Thirty-four patients who underwent pre- and postoperative physical assessment were evaluated. Nine patients were excluded because they were discharged within 14 days after surgery $(n=3)$, were unable to walk without assistance due to invasive pharyngolaryngectomy $(n=2)$, were postoperatively admitted to the Intensive Care Unit $(n=2)$, and had atrial fibrillation $(n=1)$, and physiological status was evaluated 3 weeks after surgery $(n=1)$. The tumors were staged according to the seventh edition of the Union for International Cancer Control TNM staging system, and the tumor grades were classified according to the WHO classification of histological differentiation. The severity of postoperative complications was classified using the Clavien-Dindo classification [20]. Information about patients was collected through a review of electronic medical records.

\section{Pulmonary function tests}

Preoperative pulmonary functions were routinely measured using computerized equipment (Fudak77, Fukuda Sangyo, Tokyo, Japan) at the clinical laboratory within 30 days before the operation. As spirometric parameters,

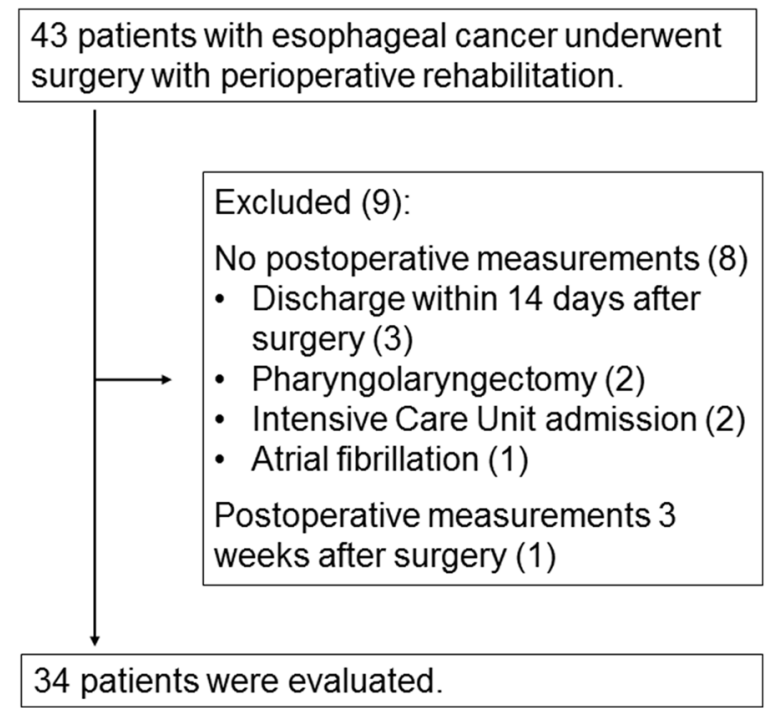

Fig. 1 Flow of participants 
vital capacity (VC), forced vital capacity (FVC), and forced expiratory volume in $1 \mathrm{~s}\left(\mathrm{FEV}_{1}\right)$ were measured. COPD was defined as an $\mathrm{FEV}_{1} / \mathrm{FVC}$ ratio $<70 \%$ without any other respiratory diseases. The predicted values for spirometry and lung volumes were calculated according to the method of the Japanese Respiratory Society [21].

\section{Measurements of physical fitness}

The 6-min walk distance (6MWD) was measured by the 6-min walk test (6MWT) according to guidelines of the American Thoracic Society [22]. During the 6MWT, oxygen saturation of a peripheral artery $\left(\mathrm{SpO}_{2}\right)$ was measured using a pulse oximeter (Pulsox-Me300; Teijin Pharma Co., Tokyo, Japan) without supplemental oxygen. Desaturation was defined as a fall in $\mathrm{SpO}_{2} \geq 4 \%$ or $\mathrm{SpO}_{2}<90 \%$ during the 6MWT [23]. Isometric knee extensor muscle strength was assessed using a hand-held dynamometer (Mutus F-100; Anima Co., Tokyo, Japan). Hand grip strength was measured using a digital dynamometer (Grip-D, Takei Co., Niigata, Japan).

\section{Assessment of anxiety, depression, and health-related QOL}

Anxiety and depression were measured using the validated Japanese version of the Hospital Anxiety and Depression Scale (HADS) [24]. The scores range from 0 to 21 for each subscale, with a score $\geq 8$ denoting a probable case. A higher score represents a higher level of anxiety or depression. Health-related QOL was assessed by the validated Japanese version of the MOS 36-item Short-Form Health Survey (SF-36) version 2, which has eight subscales and three component summary scores: a physical component summary (PCS), mental component summary (MCS), and role/social component summary (RCS) [25]. A higher SF-36 score represents a better health-related QOL. Respiratory health-related QOL was assessed by a validated Japanese version of the COPD assessment test (CAT), an eight-item questionnaire including cough, phlegm, chest tightness, breathlessness, activity limitation, confidence to leave home, sleep, and energy [26]. A higher CAT score represents a poorer respiratory health-related QOL.

\section{Rehabilitation program}

Pre- and postoperative rehabilitation was performed by specialized physical therapists (T.I., M.N, Y.M., K.H., and H.N.). The preoperative pulmonary rehabilitation protocol included (1) measurements of 6MWD, knee extensor muscle strength, and hand grip strength, (2) assessment of HADS, SF-36, and CAT, and (3) orientation to the postoperative rehabilitation program and encouragement of early mobilization. Preoperative measurements were assessed 1 to 10 days before the surgery. All patients performed the postoperative pulmonary rehabilitation, which consisted of positioning, stretching of respiratory muscles and thoracic cage, deep diaphragmatic breathing, coughing and huffing, and early mobilization from the first postoperative day. When possible, 6MWD, muscle strength, HADS, and CAT were re-evaluated 14 days after the operation.

\section{Statistical analysis}

Data were expressed as means \pm SD or median (range). The paired $t$-test or Fisher's exact test was used to evaluate statistical significance. When data failed a normality test, the Mann-Whitney $U$ test was performed. Correlations between variables were analyzed using Spearman's rank correlation coefficient. Regression analysis was used for univariate analysis and multiple regression analysis (forced entry method) was used for multivariate analysis. All analyses were conducted using SPSS ver. 19 (SPSS Inc., Tokyo, Japan). $P<0.05$ was considered statistically significant.

\section{Results}

\section{Clinical characteristics}

The characteristics and results of preoperative pulmonary function and laboratory tests of the 34 patients are shown in Table 1 . The patients were predominantly male

\begin{tabular}{|c|c|}
\hline Variable & \\
\hline Sex, male/female & $N=26 / 8$ \\
\hline Age, years (range) & $67.3 \pm 8.1(50-84)$ \\
\hline Height, cm & $163.2 \pm 7.9$ \\
\hline Weight, kg & $54.9 \pm 7.6$ \\
\hline Body mass index & $20.6 \pm 2.2$ \\
\hline Smoking history & $N=31$ \\
\hline Squamous cell carcinoma/adenocarcinoma & $N=33 / 1$ \\
\hline Clinical stage, $0-1 / 1 / / I I / I V$ & $N=12 / 4 / 16 / 2$ \\
\hline Lymphadenectomy, 1/2/3 fields & $N=1 / 24 / 9$ \\
\hline Preoperative adjuvant therapy & $N=22$ \\
\hline COPD & $N=12$ \\
\hline$\% \mathrm{VC}$ & $101.5 \pm 14.1$ \\
\hline$\% \mathrm{FEV}_{1}$ & $94.0 \pm 15.9$ \\
\hline $\mathrm{FEV}_{1} / \mathrm{FVC}, \%$ & $73.0 \pm 7.9$ \\
\hline Open surgery/video-assisted thoracic surgery & $N=31 / 3$ \\
\hline Operation time, min & $520 \pm 90$ \\
\hline Blood loss during surgery, $\mathrm{ml}$ & $719 \pm 456$ \\
\hline Intensive Care Unit stay, days & $1.3 \pm 0.6$ \\
\hline Timing of extubation, $0 / 1 / 2$ postoperative days & $N=23 / 9 / 2$ \\
\hline Hospital stay after surgery, days & $21.2 \pm 15.0$ \\
\hline Walking with support, postoperative days & $1.9 \pm 1.8$ \\
\hline
\end{tabular}

Values are numbers $(\mathrm{N})$ or mean $\pm \mathrm{SD}$. Total numbers of subjects are 34 . COPD chronic obstructive pulmonary disease, VC vital capacity, FEV , forced $^{2}$ expiratory volume in one second, FVC forced vital capacity 
(76.4\%), had a high rate of smoking history (91.2\%), and squamous cell carcinoma (97.1\%). COPD was present in 12 patients $(35.3 \%)$. The preoperative clinical stage was 0 I in 12 patients, II in 4 patients, III in 16 patients, and IV in 2 patients. Twenty-two patients $(64.7 \%)$ received some sort of induction therapy (chemotherapy or chemoradiotherapy). Thirty-one patients (91.2\%) underwent open surgery. Three $(8.8 \%)$ patients experienced postoperative pulmonary complications. Two patients developed pneumonia (Clavien-Dindo Grade II) and one patient pneumothorax (Grade I). There was no in-hospital death or reoperation after esophagectomy.

\section{Correlations between preoperative parameters}

Correlations between various parameters before the surgery are shown in Table 2. The preoperative 6MWD significantly correlated with hand grip strength (right: $r=0.562$,
$P=0.001$, left: $r=0.511, P=0.002$ ), isometric knee extensor muscle strength (right: $r=0.482, P=0.006$, left: $r=0.535$, $P=0.002)$, and SF-36 components, physical functioning $(r=0.454, P=0.013)$, general health $(r=0.465, P=0.011)$, mental health $(r=0.382, P=0.045)$, and MCS $(r=0.497$, $P=0.010)$. CAT scores showed significant inverse correlation with hand grip strength (right: $r=-0.490, P=0.005$, left: $r=-0.406, P=0.002)$ and isometric knee extensor muscle strength (right: $r=-0.491, P=0.008$, left: $r=-0.565$, $P=0.002)$. Correlations between $\mathrm{QOL}$ parameters or 6MWD and pulmonary functions before surgery are shown in Table 3. Correlations between SF-36 scores and CAT or HADS before surgery are shown in Table 4. Total CAT scores showed significant inverse correlation with most SF-36 components: physical functioning $(r=-0.384$, $P=0.040)$, general health $(r=-0.432, P=0.019)$, social functioning $(r=-0.658, P<0.001)$, vitality $(r=-0.503, P=0.005)$,

Table 2 Correlation between preoperative parameters

\begin{tabular}{|c|c|c|c|c|c|c|}
\hline \multirow[t]{2}{*}{ Parameters } & & \multirow[t]{2}{*}{ 6MWD } & \multicolumn{2}{|c|}{ Hand grip strength } & \multicolumn{2}{|c|}{ Isometric knee extensor muscle strength } \\
\hline & & & Right & Left & Right & Left \\
\hline \multirow[t]{2}{*}{ 6MWD } & $r$ & 1 & 0.562 & 0.511 & 0.482 & 0.535 \\
\hline & $P$ value & 0 & $0.001(n=34)$ & $0.002(n=34)$ & $0.006(n=31)$ & $0.002(n=31)$ \\
\hline \multirow[t]{2}{*}{ CAT scores } & r & -0.332 & -0.490 & -0.406 & -0.491 & -0.565 \\
\hline & $P$ value & $0.068(n=31)$ & $0.005(n=31)$ & $0.024(n=31)$ & $0.008(n=28)$ & $0.002(n=28)$ \\
\hline \multicolumn{7}{|l|}{ SF-36 component } \\
\hline \multirow[t]{2}{*}{ Physical functioning } & r & 0.454 & 0.137 & 0.258 & 0.350 & 0.365 \\
\hline & $P$ value & $0.013(n=29)$ & $0.478(n=29)$ & $0.177(n=29)$ & $0.080(n=26)$ & $0.067(n=26)$ \\
\hline \multirow[t]{2}{*}{ Role physical } & r & 0.334 & 0.413 & 0.490 & 0.589 & 0.473 \\
\hline & $P$ value & $0.076(n=29)$ & $0.026(n=29)$ & $0.007(n=29)$ & $0.002(n=26)$ & $0.015(n=26)$ \\
\hline \multirow[t]{2}{*}{ Bodily pain } & r & 0.126 & 0.123 & 0.166 & 0.172 & 0.125 \\
\hline & $P$ value & $0.516(n=29)$ & $0.525(n=29)$ & $0.389(n=29)$ & $0.401(n=26)$ & $0.542(n=26)$ \\
\hline \multirow[t]{2}{*}{ General health } & r & 0.465 & 0.382 & 0.367 & 0.478 & 0.376 \\
\hline & $P$ value & $0.011(n=29)$ & $0.041(n=29)$ & $0.050(n=29)$ & $0.014(n=26)$ & $0.058(n=26)$ \\
\hline \multirow[t]{2}{*}{ Social functioning } & r & 0.334 & 0.221 & 0.221 & 0.370 & 0.306 \\
\hline & $P$ value & $0.077(n=29)$ & $0.249(n=29)$ & $0.248(n=29)$ & $0.063(n=26)$ & $0.128(n=26)$ \\
\hline \multirow[t]{2}{*}{ Vitality } & r & 0.287 & 0.356 & 0.398 & 0.433 & 0.283 \\
\hline & $P$ value & $0.131(n=29)$ & $0.058(n=29)$ & $0.034(n=29)$ & $0.027(n=26)$ & $0.161(n=26)$ \\
\hline \multirow[t]{2}{*}{ Role emotional } & r & 0.243 & 0.197 & 0.317 & 0.515 & 0.385 \\
\hline & $P$ value & $0.204(n=29)$ & $0.305(n=29)$ & $0.093(n=29)$ & $0.007(n=26)$ & $0.052(n=26)$ \\
\hline \multirow[t]{2}{*}{ Mental health } & r & 0.382 & 0.124 & 0.317 & 0.355 & 0.310 \\
\hline & $P$ value & $0.045(n=28)$ & $0.529(n=28)$ & $0.093(n=28)$ & $0.081(n=25)$ & $0.131(n=25)$ \\
\hline \multirow[t]{2}{*}{ PCS } & r & 0.159 & 0.345 & 0.346 & 0.284 & 0.228 \\
\hline & $P$ value & $0.436(n=26)$ & $0.084(n=26)$ & $0.083(n=26)$ & $0.189(n=23)$ & $0.296(n=23)$ \\
\hline \multirow[t]{2}{*}{ MCS } & r & 0.497 & 0.220 & 0.180 & 0.354 & 0.349 \\
\hline & $P$ value & $0.010(n=26)$ & $0.281(n=26)$ & $0.379(n=26)$ & $0.097(n=23)$ & $0.103(n=23)$ \\
\hline \multirow[t]{2}{*}{$\mathrm{RCS}$} & r & 0.292 & 0.225 & 0.345 & 0.587 & 0.435 \\
\hline & $P$ value & $0.148(n=26)$ & $0.269(n=26)$ & $0.084(n=26)$ & $0.003(n=23)$ & $0.038(n=23)$ \\
\hline
\end{tabular}


Table 3 Correlation between preoperative parameters and pulmonary functions

\begin{tabular}{|c|c|c|c|c|c|c|}
\hline Parameters & & VC & $\% \mathrm{VC}$ & $\mathrm{FEV}_{1}$ & $\% \mathrm{FEV}_{1}$ & $\mathrm{FEV}_{1} / \mathrm{FVC}$ \\
\hline \multirow[t]{2}{*}{$6 \mathrm{MWD}(n=34)$} & $r$ & 0.502 & 0.098 & 0.579 & 0.015 & 0.291 \\
\hline & $P$ value & 0.002 & 0.581 & $<0.001$ & 0.934 & 0.095 \\
\hline \multirow[t]{2}{*}{ CAT scores $(n=31)$} & $r$ & -0.418 & -0.334 & -0.415 & -0.269 & -0.265 \\
\hline & $P$ value & 0.019 & 0.066 & 0.020 & 0.143 & 0.149 \\
\hline \multicolumn{7}{|l|}{ SF-36 component } \\
\hline \multirow[t]{2}{*}{ Physical functioning $(n=29)$} & r & 0.367 & 0.310 & 0.423 & 0.184 & 0.184 \\
\hline & $P$ value & 0.050 & 0.102 & 0.022 & 0.339 & 0.340 \\
\hline \multirow[t]{2}{*}{ Role physical $(n=29)$} & r & 0.403 & 0.009 & 0.197 & -0.315 & -0.236 \\
\hline & $P$ value & 0.030 & 0.964 & 0.305 & 0.096 & 0.218 \\
\hline \multirow[t]{2}{*}{ Bodily pain $(n=29)$} & $r$ & -0.001 & -0.050 & -0.027 & -0.246 & -0.220 \\
\hline & $P$ value & 0.997 & 0.798 & 0.891 & 0.199 & 0.251 \\
\hline \multirow[t]{2}{*}{ General health $(n=29)$} & r & 0.174 & -0.079 & 0.142 & -0.223 & -0.070 \\
\hline & $P$ value & 0.367 & 0.684 & 0.462 & 0.244 & 0.717 \\
\hline \multirow[t]{2}{*}{ Social functioning $(n=29)$} & r & 0.177 & 0.275 & 0.210 & 0.180 & 0.106 \\
\hline & $P$ value & 0.358 & 0.149 & 0.275 & 0.350 & 0.585 \\
\hline \multirow[t]{2}{*}{ Vitality $(n=29)$} & r & 0.329 & 0.112 & 0.255 & -0.122 & -0.099 \\
\hline & $P$ value & 0.081 & 0.562 & 0.182 & 0.527 & 0.611 \\
\hline \multirow[t]{2}{*}{ Role emotional $(n=29)$} & r & 0.268 & 0.007 & 0.150 & -0.186 & -0.197 \\
\hline & $P$ value & 0.160 & 0.973 & 0.437 & 0.335 & 0.307 \\
\hline \multirow[t]{2}{*}{ Mental health $(n=28)$} & r & 0.334 & 0.310 & 0.368 & 0.245 & 0.212 \\
\hline & $P$ value & 0.082 & 0.108 & 0.054 & 0.208 & 0.279 \\
\hline \multirow[t]{2}{*}{$\operatorname{PCS}(n=26)$} & r & 0.095 & -0.136 & 0.022 & -0.426 & -0.276 \\
\hline & $P$ value & 0.645 & 0.508 & 0.916 & 0.030 & 0.173 \\
\hline \multirow[t]{2}{*}{$\operatorname{MCS}(n=28)$} & $r$ & 0.217 & 0.284 & 0.291 & 0.200 & 0.157 \\
\hline & $P$ value & 0.286 & 0.159 & 0.149 & 0.327 & 0.443 \\
\hline \multirow[t]{2}{*}{$\operatorname{RCS}(n=26)$} & $r$ & 0.435 & 0.075 & 0.290 & -0.165 & -0.121 \\
\hline & $P$ value & 0.026 & 0.717 & 0.150 & 0.420 & 0.556 \\
\hline
\end{tabular}

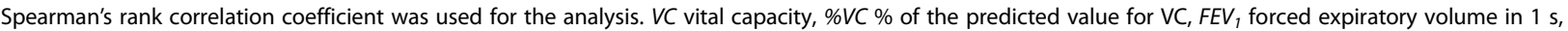
$\% F E V_{1} \%$ of the predicted value for $\mathrm{FEV}_{1}, \mathrm{FVC}$ forced vital capacity

role emotional $(r=-0.381, P=0.041)$, mental health $(r=-0.510, P=0.006)$, MCS $(r=-0.584, P=0.002)$, and RCS $(r=-0.433, P=0.027)$. HADS anxiety and depression significantly correlated with most SF-36 components. In contrast, HADS anxiety and depression did not significantly correlate with CAT scores.

\section{Correlations between postoperative parameters}

Correlations between various parameters after the surgery are shown in Table 5. The postoperative 6MWD significantly correlated with postoperative left isometric knee muscle extensor strength $(r=0.526, P=0.003)$.

\section{Comparison between pre- and postoperative measurements}

Next, the effects of esophagectomy on physical and psychological status were examined. Comparisons and changes of $6 \mathrm{MWD}$, desaturation during the 6MWT, muscle strength, HADS, and CAT before and after surgery are shown in Table 6. The post-operative 6MWD $(409 \pm 108 \mathrm{~m})$ was significantly shorter than the preoperative value $(496 \pm 76 \mathrm{~m}, P<0.001)$. Muscle strength results showed that both right and left hand grip strengths were significantly decreased after the operation $(P=0.01)$. Left side isometric knee extensor muscle strength was significantly decreased after the operation $(P=0.02)$. That of the right side was also decreased after the operation, but the difference was not statistically significant level $(P=0.08)$. The number of patients whose HADS anxiety score was $\geq 8$ increased from 4 to 8 after surgery, although the difference did not reach a statistically significant level by Fisher's exact test $(P=0.31)$. CAT scores significantly increased after surgery $(P=0.02)$.

Two different surgical techniques, open surgery for 31 patients and video-assisted thoracic (closed) surgery for three patients, were performed (Table 1). Demographics 
Table 4 Correlation between SF-36 and CAT or HADS before surgery

\begin{tabular}{|c|c|c|c|c|}
\hline SF-36 component & & CAT & $\begin{array}{l}\text { HADS } \\
\text { anxiety }\end{array}$ & $\begin{array}{l}\text { HADS } \\
\text { depression }\end{array}$ \\
\hline \multirow[t]{2}{*}{ Physical functioning } & $r$ & -0.384 & -0.339 & -0.500 \\
\hline & $P$ value & 0.040 & 0.072 & 0.006 \\
\hline \multirow[t]{2}{*}{ Role physical } & r & -0.323 & -0.745 & -0.557 \\
\hline & $P$ value & 0.088 & $<0.001$ & 0.002 \\
\hline \multirow[t]{2}{*}{ Bodily pain } & r & -0.167 & -0.368 & -0.252 \\
\hline & $P$ value & 0.385 & 0.049 & 0.187 \\
\hline \multirow[t]{2}{*}{ General health } & r & -0.432 & -0.543 & -0.321 \\
\hline & $P$ value & 0.019 & 0.002 & 0.090 \\
\hline \multirow[t]{2}{*}{ Social functioning } & r & -0.658 & -0.464 & -0.403 \\
\hline & $P$ value & $<0.001$ & 0.011 & 0.030 \\
\hline \multirow[t]{2}{*}{ Vitality } & r & -0.503 & -0.448 & -0.554 \\
\hline & $P$ value & 0.005 & 0.015 & 0.002 \\
\hline \multirow[t]{2}{*}{ Role emotional } & r & -0.381 & -0.593 & -0.470 \\
\hline & $P$ value & 0.041 & 0.001 & 0.010 \\
\hline \multirow[t]{2}{*}{ Mental health $(n=28)$} & r & -0.510 & -0.379 & -0.563 \\
\hline & $P$ value & 0.006 & 0.047 & 0.002 \\
\hline \multirow[t]{2}{*}{ PCS $(n=26)$} & r & -0.245 & -0.364 & -0.266 \\
\hline & $P$ value & 0.228 & 0.067 & 0.188 \\
\hline \multirow[t]{2}{*}{$\operatorname{MCS}(n=26)$} & r & -0.584 & -0.361 & -0.317 \\
\hline & $P$ value & 0.002 & 0.070 & 0.115 \\
\hline \multirow[t]{2}{*}{$\operatorname{RCS}(n=26)$} & r & -0.433 & -0.653 & -0.648 \\
\hline & $P$ value & 0.027 & $<0.001$ & $<0.001$ \\
\hline
\end{tabular}

Spearman's rank correlation coefficient was used for the analysis. $N=29$, otherwise indicated. HADS the Hospital Anxiety and Depression Scale

and data of pre- and postoperative measurements of three patients who underwent video-assisted thoracic surgery are shown in Additional file 1: Table S1. The mean values of postoperative 6MWD and changes of 6MWD after the surgery were $364 \mathrm{~m}$ and $-60 \mathrm{~m}$. The mean changes of right and left hand grip strengths and right isometric knee extensor muscle strength were $-3.8 \mathrm{kgf},-2.5 \mathrm{kgf}$, and $-2.3 \mathrm{kgf}$, respectively. Left isometric knee extensor muscle strength was increased in two patients, and the mean changes were $1.0 \mathrm{kgf}$.
Effects of COPD and preoperative chemoradiotherapy The effects of comorbidity of COPD on physical and QOL parameters were examined. The parameters of patients with and without COPD are compared in Table 7. Preoperative $\% \mathrm{FEV}_{1}(P<0.001), \mathrm{FEV}_{1} / \mathrm{FVC}(P<0.001)$, postoperative 6MWD $(P=0.034)$, and preoperative left isometric knee extensor muscle strength $(P=0.018)$ were significantly lower in patients with COPD than those without COPD. There was no significant difference in preoperative SF-36 components between the groups.

We also compared the results of physical and QOL parameters of patients with and without preoperative chemotherapy or radiotherapy (Table 8). Among preoperative SF-36 components, role emotional and PCS scores of patients undergoing chemoradiotherapy were significantly lower than those without $(P=0.019)$. There was no significant difference in other parameters between the groups.

\section{Factors affecting postoperative 6MWD}

Next, we aimed to identify pre- and intraoperative factors affecting the postoperative loss of exercise capacity. Changes in 6MWD before and after surgery were chosen because the $6 \mathrm{MWT}$ is a validated method to assess functional exercise capacity and efficacy of pulmonary rehabilitation [27]. Results of the univariate regression analysis showed that the preoperative PCS, a component of SF-36, significantly correlated with decrease of 6MWD ( $r=0.437, P=0.033$ ) (Table 9). On the other hand, preoperative 6MWD, pulmonary functions, muscle strength, COPD comorbidity, chemoradiotherapy, blood loss during surgery, and operation time did not predict changes in 6MWD (Table 9). Multiple regression analysis including all relevant variables with $P$ values $<0.10$ in univariate analysis showed that only PCS significantly correlated with changes in 6MWD $(r=0.488, P=0.027)$ (Table 9). There was a trend toward a greater risk of loss of $6 \mathrm{MWD}$ as preoperative \%VC decreased $(P=0.077)$.

\section{Discussion}

The main findings of the present study of patients with esophageal cancer who underwent esophagectomy with

Table 5 Correlation between postoperative parameters

\begin{tabular}{|c|c|c|c|c|c|c|}
\hline \multirow[t]{2}{*}{ Parameters } & & \multirow[t]{2}{*}{ 6MWD } & \multicolumn{2}{|c|}{ Hand grip strength } & \multicolumn{2}{|c|}{ Isometric knee extensor muscle strength } \\
\hline & & & Right & Left & Right & Left \\
\hline \multirow[t]{2}{*}{ 6MWD } & r & 1 & 0.159 & 0.071 & 0.325 & 0.526 \\
\hline & $P$ value & 0 & $0.394(n=31)$ & $0.704(n=31)$ & $0.085(n=29)$ & $0.003^{*}(n=29)$ \\
\hline \multirow[t]{2}{*}{ CAT scores } & r & -0.053 & -0.020 & 0.014 & -0.421 & -0.383 \\
\hline & $P$ value & $0.816(n=22)$ & $0.927(n=23)$ & $0.948(n=23)$ & $0.058(n=21)$ & $0.086(n=21)$ \\
\hline
\end{tabular}

Spearman's rank correlation coefficient was used for the analysis. ${ }^{*} P<0.05$ 
Table 6 Comparison of 6MWD, muscle strength, and HADS before and after surgery

\begin{tabular}{|c|c|c|c|c|}
\hline & Before & After surgery & $P$ value & Changes \\
\hline 6MWD, $\mathrm{m}(n=32)$ & $494 \pm 76$ & $409 \pm 108$ & $0.001>^{*}$ & $-85 \pm 88$ \\
\hline Desaturation during $6 \mathrm{MWT}^{\mathrm{a}}$ & $N=5$ & $N=5$ & 1 & \\
\hline \multicolumn{5}{|l|}{ Hand grip strength, kgf $(n=33)$} \\
\hline Right & $30.6 \pm 9.1$ & $28.7 \pm 8.6$ & $0.01^{*}$ & $-1.9 \pm 3.9$ \\
\hline Left & $28.8 \pm 8.6$ & $27.5 \pm 7.7$ & $0.01^{*}$ & $-1.3 \pm 2.8$ \\
\hline \multicolumn{5}{|c|}{ Isometric knee extensor muscle strength, kgf $(n=31)$} \\
\hline Right & $26.0 \pm 8.5$ & $24.7 \pm 8.2$ & 0.08 & $-1.3 \pm 3.8$ \\
\hline Left & $25.2 \pm 9.4$ & $22.9 \pm 7.8$ & $0.02^{*}$ & $-2.3 \pm 4.9$ \\
\hline HADS anxiety $(n=23)$ & $5.4 \pm 2.9$ & $5.1 \pm 4.0$ & 0.76 & $-0.3 \pm 4.0$ \\
\hline Scores $\geq 8$ & $N=4$ & $N=8$ & 0.31 & \\
\hline HADS depression $(n=23)$ & $5.7 \pm 3.7$ & $5.4 \pm 3.8$ & 0.54 & $-0.3 \pm 2.3$ \\
\hline Scores $\geq 8$ & $N=6$ & $N=7$ & 1 & \\
\hline CAT $(n=24)$ & $10.4 \pm 5.6$ & $15.9 \pm 7.3$ & $0.02^{*}$ & $5.5 \pm 7.5$ \\
\hline
\end{tabular}

Values are mean $\pm \mathrm{SD}$ and compared by paired t-test or Fisher's exact test. ${ }^{\mathrm{a}}$ Desaturation was defined as a fall in $\mathrm{SpO}_{2} \geq 4 \%$ or $\mathrm{SpO} 2<90 \%$ during the $6 \mathrm{MWT}_{2}$. ${ }^{*} P<0.05$

perioperative pulmonary rehabilitation were: 1) 6MWD and skeletal muscle strength had significantly decreased and CAT scores had increased 2 weeks after surgery, 2) PCS, a component of SF-36, significantly correlated with the decrease of 6MWD, and 3) comorbidity of COPD had a significant impact on health-related QOL, muscle strength, and 6MWD. To our knowledge, this is the first study to characterize the status of physical fitness, exercise capacity, health-related QOL, anxiety, and depression in patients with esophageal cancer before and after the surgery.

The $6 \mathrm{MWT}$ is a simple but well validated method to assess functional exercise capacity in patients with pulmonary and cardiovascular diseases [22] and the efficacy of pulmonary rehabilitation [27]. In the present study, preoperative 6MWD positively correlated with hand grip and isometric knee extensor muscle strength. It is expected that postoperative pulmonary rehabilitation helped maintain and recover the physical status of patients. However, the postoperative 6MWD and muscle strength were significantly lower than the preoperative values. Importantly, a mean decrease in the 6MWD of $85 \mathrm{~m}$ exceeded the clin-

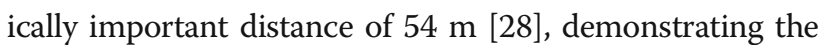
significant short-term impact of esophagectomy on exercise capacity. Even in the three patients who underwent video-assisted thoracic surgery, the mean decrease in 6MWD was $60 \mathrm{~m}$, above the clinically important value. Our results were consistent with the previous report by Tatematsu et al. that 6MWD and knee-extensor muscle strength, which were measured on the day of hospital discharge (median 21 days after surgery), were significantly decreased after esophagectomy [13]. Tatematsu et al. also reported that the change in the physical functional score on EORTC QLQ-C30 was significantly affected by that in the 6MWD by multiple regression analysis [13]. In our study, results of multiple and univariate regression analysis show that the loss of 6MWD was significantly affected by the preoperative SF-36 physical component PCS. In contrast, comorbidity of COPD, preoperative adjuvant therapy, pulmonary function test results, operation duration, or blood loss during surgery did not affect the change in 6MWD, consistent with the results of Tatematsu et al. These findings indicate that the 6MWT is a convenient and useful tool to assess the physical status in order to plan a perioperative rehabilitation program for patients with esophageal cancer.

Long-term cigarette smoking is an important risk factor for developing COPD as well as squamous cell carcinoma of the esophagus. It has been reported that COPD is one of the predictors of postoperative mortality after esophagectomy [5]. In our study, $91.2 \%$ of patients were smokers, and the prevalence of COPD was relatively high (35.3\%). Moreover, both physical and QOL parameters were affected by comorbidity with COPD. The CAT is a validated questionnaire designed to assess and quantify the impact of COPD symptoms on healthrelated QOL [26]. The CAT scores strongly correlate with scores on the St. George Respiratory Questionnaire, a tool to evaluate the respiratory-related QOL [26]. Significant correlations between scores of total CAT and SF-36, a measure of the general health-related QOL, were found in our cohort, consistent with findings in COPD patients [29]. Preoperative CAT scores were significantly higher and postoperative 6MWD and left hand grip strength were significantly lower in patients with COPD than those without. In addition, postoperative CAT scores were significantly higher than preoperative scores, suggesting the impact of esophagectomy on 
Table 7 Comparison of data with and without COPD

\begin{tabular}{|c|c|c|c|}
\hline & Non-COPD $(n=22)$ & $\operatorname{COPD}(n=12)$ & $P$ value \\
\hline Pre $\% \mathrm{FEV}_{1}$ & $101.3 \pm 12.7$ & $75.2 \pm 21.1$ & $<0.001^{*}$ \\
\hline Pre $\mathrm{FEV}_{1} / \mathrm{FVC}, \%$ & $77.3 \pm 5.7$ & $60.5 \pm 16.3$ & $<0.001^{*}$ \\
\hline Pre $6 \mathrm{MWD}, \mathrm{m}$ & $509 \pm 80$ & $466 \pm 60$ & 0.127 \\
\hline Desaturation during $6 \mathrm{MWT}^{\mathrm{a}}$ & $N=3$ & $N=2$ & 0.580 \\
\hline Post 6MWD, m & $438 \pm 100(n=21)$ & $351 \pm 105(n=11)$ & $0.034^{*}$ \\
\hline Desaturation during $6 \mathrm{MWT}^{\mathrm{a}}$ & $N=2$ & $N=3$ & 0.290 \\
\hline Changes in 6MWD, $\mathrm{m}$ & $-70 \pm 83(n=21)$ & $-114 \pm 98(n=11)$ & 0.123 \\
\hline \multicolumn{4}{|l|}{ Pre hand grip strength, kgf } \\
\hline Right & $32.4 \pm 8.4$ & $28.4 \pm 10.5$ & 0.204 \\
\hline Left & $30.7 \pm 8.8$ & $27.0 \pm 9.4$ & 0.204 \\
\hline \multicolumn{4}{|l|}{ Post hand grip strength, kgf } \\
\hline Right & $29.6 \pm 7.9(n=21)$ & $26.6 \pm 9.7$ & 0.152 \\
\hline Left & $28.7 \pm 7.3(n=21)$ & $25.8 \pm 8.0$ & 0.242 \\
\hline \multicolumn{4}{|c|}{ Pre isometric knee extensor muscle strength, kgf } \\
\hline Right & $26.7 \pm 8.2(n=20)$ & $24.7 \pm 9.4(n=11)$ & 0.502 \\
\hline Left & $27.6 \pm 8.9(n=20)$ & $20.1 \pm 9.1(n=11)$ & $0.018^{*}$ \\
\hline \multicolumn{4}{|c|}{ Post isometric knee extensor muscle strength, kgf } \\
\hline Right & $25.8 \pm 8.3(n=20)$ & $22.8 \pm 8.0(n=11)$ & 0.183 \\
\hline Left & $24.9 \pm 7.7(n=20)$ & $19.3 \pm 6.9(n=11)$ & $0.020^{*}$ \\
\hline Pre HADS anxiety & $6.1 \pm 2.8(n=21)$ & $4.5 \pm 3.2(n=10)$ & 0.135 \\
\hline Scores $\geq 8$ & $N=5$ & $N=2$ & 1 \\
\hline Pre HADS depression & $5.6 \pm 3.2(n=21)$ & $5.5 \pm 4.1(n=10)$ & 0.852 \\
\hline Scores $\geq 8$ & $N=5$ & $N=4$ & 0.781 \\
\hline Post HADS anxiety & $4.8 \pm 3.3(n=15)$ & $5.6 \pm 5.4(n=8)$ & 0.925 \\
\hline Scores $\geq 8$ & $N=4$ & $N=4$ & 0.676 \\
\hline Post HADS depression & $5.7 \pm 3.8(n=15)$ & $4.9 \pm 4.1(n=8)$ & 0.681 \\
\hline Scores $\geq 8$ & $N=5$ & $N=2$ & 1 \\
\hline Pre CAT $(n=31)$ & $8.1 \pm 5.5(n=21)$ & $14.2 \pm 5.5(n=10)$ & $0.008^{*}$ \\
\hline Post CAT $(n=24)$ & $14.1 \pm 5.3(n=16)$ & $19.6 \pm 9.6(n=8)$ & 0.136 \\
\hline \multicolumn{4}{|l|}{ Pre SF-36 component } \\
\hline Physical functioning & $49.5 \pm 15.1(n=19)$ & $40.9 \pm 15.5(n=10)$ & 0.308 \\
\hline Role physical & $37.6 \pm 19.3(n=19)$ & $38.1 \pm 21.6(n=10)$ & 0.456 \\
\hline Bodily pain & $44.8 \pm 12.9(n=19)$ & $41.4 \pm 24.5(n=10)$ & 0.804 \\
\hline General health & $45.3 \pm 9.5(n=19)$ & $45.4 \pm 11.4(n=10)$ & 0.946 \\
\hline Vitality & $43.2 \pm 17.6(n=19)$ & $39.0 \pm 18.4(n=10)$ & 0.804 \\
\hline Social functioning & $49.0 \pm 11.2(n=19)$ & $38.8 \pm 17.3(n=10)$ & 0.069 \\
\hline Role emotional & $41.3 \pm 18.2(n=19)$ & $40.7 \pm 17.0(n=10)$ & 0.604 \\
\hline Mental health & $49.3 \pm 14.3(n=19)$ & $38.4 \pm 12.7(n=9)$ & 0.061 \\
\hline PCS & $46.7 \pm 5.8(n=19)$ & $52.5 \pm 9.7(n=7)$ & 0.209 \\
\hline MCS & $51.2 \pm 10.1(n=19)$ & $45.5 \pm 9.6(n=7)$ & 0.073 \\
\hline RCS & $38.1 \pm 12.4(n=19)$ & $36.3 \pm 23.3(n=7)$ & 0.955 \\
\hline
\end{tabular}

Values are mean $\pm \mathrm{SD}$ and compared by paired t-test, Mann-Whitney $\mathrm{U}$ test or Fisher's exact test. ${ }^{*} P<0.05$. ${ }^{\mathrm{a}}$ Desaturation was defined as a fall in $\mathrm{SpO} \mathrm{O}_{2} \geq 4 \%$ or $\mathrm{SpO}_{2}<90 \%$. The HADS score $\geq 8$ denotes a probable case. Pre preoperative, Post postoperative 
Table 8 Comparison of data with and without chemoradiotherapy

\begin{tabular}{|c|c|c|c|}
\hline & Without $(n=12)$ & Chemotherapy and/or radiotherapy $(n=22)$ & $P$ value \\
\hline$\% \mathrm{FEV}_{1}$ & $93.3 \pm 20.4$ & $94.5 \pm 13.9$ & 0.466 \\
\hline $\mathrm{FEV}_{1} / \mathrm{FVC}, \%$ & $69.8 \pm 7.7$ & $74.8 \pm 7.8$ & 0.136 \\
\hline Pre $6 \mathrm{MWD}, \mathrm{m}$ & $485 \pm 59$ & $499 \pm 82$ & 0.790 \\
\hline Desaturation during $6 \mathrm{MWT}^{\mathrm{a}}$ & $N=4$ & $N=1$ & 1 \\
\hline Post 6MWD, m & $389 \pm 109$ & $421 \pm 109(n=20)$ & 0.654 \\
\hline Desaturation during $6 \mathrm{MWT}^{\mathrm{a}}$ & $N=0$ & $N=5$ & 0.155 \\
\hline Changes in $6 \mathrm{MWD}, \mathrm{m}$ & $-97 \pm 61$ & $-78 \pm 104(n=20)$ & 0.158 \\
\hline \multicolumn{4}{|l|}{ Pre hand grip strength, kgf } \\
\hline Right & $33.0 \pm 12.0$ & $29.9 \pm 7.4$ & 0.327 \\
\hline Left & $31.8 \pm 11.0$ & $28.1 \pm 7.8$ & 0.261 \\
\hline \multicolumn{4}{|l|}{ Post hand grip strength, kgf } \\
\hline Right & $30.8 \pm 11.3(n=11)$ & $27.7 \pm 7.0$ & 0.560 \\
\hline Left & $28.4 \pm 8.9(n=11)$ & $27.1 \pm 7.2$ & 0.693 \\
\hline
\end{tabular}

Pre isometric knee extensor muscle strength, kgf

$\begin{array}{llll}\text { Right } & 30.0 \pm 9.4 & 23.4 \pm 7.0(n=20) & 0.059 \\ \text { Left } & 28.8 \pm 11.6 & 23.0 \pm 7.2(n=20) & 0.269\end{array}$

Post isometric knee extensor muscle strength, kgf

\begin{tabular}{|c|c|c|c|}
\hline Right & $28.3 \pm 9.0$ & $22.5 \pm 7.0(n=20)$ & 0.120 \\
\hline Left & $25.4 \pm 8.8$ & $21.3 \pm 6.8(n=20)$ & 0.287 \\
\hline Pre HADS anxiety & $4.9 \pm 3.5$ & $6.0 \pm 2.6(n=19)$ & 0.367 \\
\hline Scores $\geq 8$ & $N=3$ & $N=4$ & 1 \\
\hline Pre HADS depression & $4.5 \pm 2.9$ & $6.2 \pm 3.7(n=19)$ & 0.287 \\
\hline Scores $\geq 8$ & $N=3$ & $N=5$ & 1 \\
\hline Post HADS anxiety & $5.3 \pm 4.8(n=7)$ & $5.0 \pm 3.8(n=16)$ & 1 \\
\hline Scores $\geq 8$ & $N=2$ & $N=6$ & 1 \\
\hline Post HADS depression & $3.3 \pm 2.6(n=7)$ & $6.3 \pm 4.0(n=16)$ & 0.103 \\
\hline Scores $\geq 8$ & $N=2$ & $N=9$ & 0.682 \\
\hline Pre CAT $(n=31)$ & $9.3 \pm 6.4$ & $10.6 \pm 6.1(n=19)$ & 0.509 \\
\hline Post CAT $(n=24)$ & $13.7 \pm 8.6(n=6)$ & $16.7 \pm 6.9(n=18)$ & 0.343 \\
\hline \multicolumn{4}{|l|}{ re SF-36 component } \\
\hline Physical functioning & $51.7 \pm 20.1(n=11)$ & $43.4 \pm 11.6(n=18)$ & 0.146 \\
\hline Role physical & $46.2 \pm 25.3(n=11)$ & $32.6 \pm 13.8(n=18)$ & 0.084 \\
\hline Bodily pain & $38.7 \pm 21.0(n=11)$ & $46.7 \pm 14.6(n=18)$ & 0.387 \\
\hline General health & $49.2 \pm 7.9(n=11)$ & $42.9 \pm 10.6(n=18)$ & 0.055 \\
\hline Vitality & $48.1 \pm 19.0(n=11)$ & $37.9 \pm 16.1(n=18)$ & 0.188 \\
\hline Social functioning & $45.0 \pm 18.1(n=11)$ & $45.7 \pm 11.7(n=18)$ & 0.580 \\
\hline Role emotional & $50.2 \pm 19.7(n=11)$ & $35.5 \pm 13.7(n=18)$ & $0.049^{*}$ \\
\hline Mental health & $47.1 \pm 17.4(n=10)$ & $45.1 \pm 13.2(n=18)$ & 1.000 \\
\hline PCS & $53.2 \pm 6.6(n=8)$ & $46.0 \pm 6.6(n=18)$ & $0.019^{*}$ \\
\hline MCS & $48.9 \pm 8.5(n=8)$ & $50.0 \pm 10.8(n=18)$ & 0.807 \\
\hline RCS & $44.3 \pm 11.3(n=8)$ & $32.5 \pm 16.0(n=18)$ & 0.090 \\
\hline
\end{tabular}

Values are mean $\pm \mathrm{SD}$ and compared by paired t-test, Mann-Whitney $\mathrm{U}$ test or Fisher's exact test. ${ }^{\mathrm{a}}$ Desaturation was defined as a fall in $\mathrm{SpO}_{2} \geq 4 \%$ or $\mathrm{SpO}_{2}<90 \%$ 
Table 9 Correlations between changes in 6MWD after esophagectomy and other parameters

\begin{tabular}{|c|c|c|c|c|}
\hline \multirow[t]{2}{*}{ Parameters } & \multicolumn{2}{|l|}{ Univariate analysis } & \multicolumn{2}{|l|}{ Multivariate analysis } \\
\hline & Standardized partial regression coefficient & $P$ value & Standardized partial regression coefficient & $P$ value \\
\hline \multicolumn{5}{|l|}{ Preoperative parameters } \\
\hline Body mass index & -0.056 & 0.760 & ND & ND \\
\hline$\% \mathrm{VC}$ & -0.327 & 0.068 & $-0.573(n=23)$ & 0.077 \\
\hline$\% \mathrm{FEV}_{1}$ & -0.302 & 0.093 & $0.369(n=23)$ & 0.273 \\
\hline $6 \mathrm{MWD}$ & 0.153 & 0.403 & ND & ND \\
\hline \multicolumn{5}{|l|}{ Hand grip strength } \\
\hline Right & 0.273 & 0.130 & ND & ND \\
\hline Left & 0.254 & 0.162 & ND & ND \\
\hline \multicolumn{5}{|l|}{ Isometric knee extensor muscle strength } \\
\hline Right $(n=29)$ & 0.028 & 0.885 & ND & ND \\
\hline Left $(n=29)$ & -0.101 & 0.601 & ND & ND \\
\hline CAT $(n=29)$ & 0.220 & 0.251 & ND & ND \\
\hline \multicolumn{5}{|l|}{ SF-36 component } \\
\hline Physical functioning $(n=27)$ & -0.186 & 0.353 & ND & ND \\
\hline Role physical $(n=27)$ & -0.008 & 0.968 & ND & ND \\
\hline Bodily pain $(n=27)$ & 0.283 & 0.153 & ND & ND \\
\hline General health $(n=27)$ & 0.049 & 0.809 & ND & ND \\
\hline Social functioning $(n=27)$ & -0.217 & 0.276 & ND & ND \\
\hline Vitality $(n=27)$ & 0.210 & 0.293 & ND & ND \\
\hline Role emotional $(n=27)$ & 0.028 & 0.891 & ND & ND \\
\hline Mental health $(n=26)$ & -0.145 & 0.480 & ND & ND \\
\hline PCS $(n=24)$ & 0.437 & $0.033^{*}$ & $0.488(n=23)$ & $0.027^{*}$ \\
\hline MCS $(n=24)$ & -0.073 & 0.734 & ND & ND \\
\hline $\operatorname{RCS}(n=24)$ & 0.115 & 0.593 & ND & ND \\
\hline With-without COPD & 0.241 & 0.184 & ND & ND \\
\hline With-without chemo-radio therapy & -0.103 & 0.575 & ND & ND \\
\hline \multicolumn{5}{|l|}{ Intraoperative parameters } \\
\hline Blood loss during surgery & 0.145 & 0.428 & ND & ND \\
\hline Operation time & 0.145 & 0.430 & ND & ND \\
\hline \multicolumn{5}{|l|}{ Postoperative parameters } \\
\hline Postoperative hospital stays & 0.046 & 0.802 & ND & ND \\
\hline \multicolumn{5}{|l|}{ Changes in hand grip strength } \\
\hline Right $(n=31)$ & 0.153 & 0.412 & ND & ND \\
\hline Left $(n=31)$ & 0.143 & 0.442 & ND & ND \\
\hline \multicolumn{5}{|c|}{ Changes in isometric knee extensor muscle strength } \\
\hline Right $(n=29)$ & 0.045 & 0.815 & ND & ND \\
\hline Left $(n=29)$ & 0.089 & 0.646 & ND & ND \\
\hline Changes in CAT scores $(n=23)$ & -0.219 & 0.315 & ND & ND \\
\hline
\end{tabular}

The multivariate analysis includes relevant variables with $P$ values $<0.10$ in univariate analysis (preoperative $\% \mathrm{VC}$ and $\% \mathrm{FEV}$, and $\mathrm{PCS}$ ). $N D$ not done. ${ }^{*} P<0.05$.

$N=32$ otherwise indicated

respiratory-related QOL. Although the use of CAT for assessment of the respiratory-related QOL after surgery such as esophagectomy has not been validated yet, CAT was used before and after the surgery for the following reasons. First, almost all the patients in our cohort were smokers with a high prevalence of COPD. Second, pulmonary rehabilitation was the main objective of our perioperative rehabilitation program in order to prevent 
pulmonary complications after esophagectomy. Third, a recent study demonstrated that the CAT is beneficial to assess respiratory symptom and complications even in smokers without COPD [30]. Future studies are required to validate the use of CAT to assess respiratory-related QOL in patients who receive perioperative pulmonary rehabilitation. It would also be useful to evaluate the correlation between scores of CAT and QOL questionnaires specific for cancer and esophageal diseases such as the EORTC QLQ-C30 [14] and EORTC QLQ-OES24 [15].

The long-term impacts of esophagectomy on physical, QOL, or mental status after discharge have been investigated by other groups [11, 15, 31, 32]. In contrast, there is little information on postoperative physical and QOL status before discharge. The major purpose of our study was to evaluate how the physical, mental, and QOL parameters have recovered 2 weeks after esophagectomy during the hospital stay. Severer cases were excluded from the analysis because of gait disturbance 2 weeks after the surgery (Fig. 1). The incidence of pulmonary complications $(8.8 \%)$ was lower than that in previous reports $(15-36 \%)$ [4, 33, 34]. Thus, our patients reflect a relatively good clinical course shortly after the esophagectomy.

This study has several limitations. The data were collected retrospectively from patients who underwent esophagectomy. We did not aim to determine the factors that predict postoperative complications or examine the effectiveness of perioperative pulmonary rehabilitation either. It is impossible to clarify whether the rehabilitation was beneficial for health outcomes after the esophagectomy from the present study design. A previous study demonstrated that intensive prehabilitation reduced postoperative pulmonary complications after esophagectomy [10], indicating that improvement of physical fitness before the surgery may lead to better clinical outcomes after esophagectomy. Our findings demonstrated both the physical and QOL status of inhospital patients two weeks after esophagectomy with perioperative rehabilitation. Further improvements, both from the viewpoint of minimally invasive surgery and perioperative management, are warranted. Prospective studies with a larger number of subjects including patients both with and without pulmonary rehabilitation are necessary to characterize the risk factors of postoperative complications and to improve the perioperative rehabilitation programs.

\section{Conclusion}

Our results indicate that esophagectomy is detrimental to health-related QOL and physical fitness at two weeks after surgery. Further investigation is required to establish a strategy for perioperative rehabilitation to improve postoperative outcomes.

\section{Additional files}

Additional file 1: Table S1. Data of three patients who underwent video-assisted thoracic surgery. (DOCX $19 \mathrm{~kb}$ )

Additional file 2: Table S2. The datasets of 34 patients. (XLSX 23 kb)

\section{Abbreviations}

6MWD: 6-min walk distance; 6MWT: 6-min walk test; CAT: COPD assessment test; COPD: Chronic obstructive pulmonary disease; EORTC QLQ: European Organization for the Research and Treatment of Cancer QOL Core

Questionnaire; FEV ${ }_{1}$ : Forced expiratory volume in one second; FVC: Forced vital capacity; HADS: Hospital Anxiety and Depression Scale; MCS: Mental component summary; PCS: Physical component summary; QOL: Quality of life; RCS: Role/social component summary; SF-36: The MOS 36-item ShortForm Health Survey version 2; $\mathrm{SpO}_{2}$ : Oxygen saturation of a peripheral artery; VC: Vital capacity

\section{Acknowledgements}

The authors thank Ms. Katherine Ono for providing language help.

\section{Funding}

This work was supported by Grant in Aid (No. 16 K21081 to T. Inoue) from the Ministry of Education, Culture, Sports, Science and Technology of Japan.

\section{Availability of data and material}

The dataset supporting the conclusions of this article is available in Additional file 2: Table S2.

\section{Authors' contributions}

SI was responsible for the present study's concept and design, as well as for data acquisition, analysis, interpretation, and drafting of the manuscript. Tl, $M N, H A, Y M, K H, H N$, and YNiwa undertook the measurements and analyses of data. TI, MK, and YK analyzed the data and wrote the manuscript. MA was responsible for the statistical analysis. YK, YNis and $\mathrm{YH}$ supervised the research work. All the authors have approved the submission of the manuscript.

\section{Competing interests}

The authors declare they have no competing interests.

\section{Consent for publication}

The study information was disclosed to website of Nagoya University Hospital. The patients are able to access to the study information through internet so that they retain the right to refuse to have their data included in the analysis.

\section{Ethics approval and consent to participate}

This retrospective study was approved by the local ethics committee of Nagoya University Hospital (approval No. 2015-0413). No patient identifiers were included. Informed consent to participate and publish was not required for this retrospective analysis.

\section{Author details}

${ }^{1}$ Department of Rehabilitation, Nagoya University School of Medicine, Nagoya 466-8550, Japan. ²Department of Respiratory Medicine, Nagoya University School of Medicine, Nagoya 466-8550, Japan. ${ }^{3}$ Center for Advanced Medicine and Clinical Research, Nagoya University School of Medicine, Nagoya 466-8550, Japan. ${ }^{4}$ Gastroenterological Surgery II, Nagoya University School of Medicine, Nagoya 466-8550, Japan.

Received: 12 May 2016 Accepted: 25 October 2016

Published online: 03 November 2016

\section{References}

1. Takeuchi H, Miyata H, Gotoh M, Kitagawa Y, Baba H, Kimura W, et al. A risk model for esophagectomy using data of 5354 patients included in a Japanese nationwide web-based database. Ann Surg. 2014;260:259-66. 
2. Grotenhuis BA, Wijnhoven BP, Grune F, van Bommel J, Tilanus HW, van Lanschot JJ. Preoperative risk assessment and prevention of complications in patients with esophageal cancer. J Surg Oncol. 2010;101:270-8.

3. McCulloch P, Ward J, Tekkis PP. Mortality and morbidity in gastrooesophageal cancer surgery: initial results of ASCOT multicentre prospective cohort study. BMJ. 2003:327:1192-7.

4. Avendano CE, Flume PA, Silvestri GA, King LB, Reed CE. Pulmonary complications after esophagectomy. Ann Thorac Surg. 2002;73:922-6.

5. Walters DM, McMurry TL, Isbell JM, Stukenborg GJ, Kozower BD. Understanding mortality as a quality indicator after esophagectomy. Ann Thorac Surg. 2014;98:506-11. discussion 11-2.

6. Nagamatsu Y, Shima I, Yamana H, Fujita H, Shirouzu K, Ishitake T. Preoperative evaluation of cardiopulmonary reserve with the use of expired gas analysis during exercise testing in patients with squamous cell carcinoma of the thoracic esophagus. J Thorac Cardiovasc Surg. 2001;121:1064-8.

7. Feeney C, Reynolds JV, Hussey J. Preoperative physical activity levels and postoperative pulmonary complications post-esophagectomy. Dis Esophagus. 2011;24:489-94

8. Tatematsu N, Park M, Tanaka E, Sakai Y, Tsuboyama T. Association between physical activity and postoperative complications after esophagectomy for cancer: a prospective observational study. Asian Pac J Cancer Prev. 2013;14:47-51.

9. Yamana I, Takeno S, Hashimoto T, Maki K, Shibata R, Shiwaku H, et al. Randomized controlled study to evaluate the efficacy of a preoperative respiratory rehabilitation program to prevent postoperative pulmonary complications after esophagectomy. Dig Surg. 2015;32:331-7.

10. Inoue J, Ono R, Makiura D, Kashiwa-Motoyama M, Miura Y, Usami M, et al. Prevention of postoperative pulmonary complications through intensive preoperative respiratory rehabilitation in patients with esophageal cancer. Dis Esophagus. 2013;26:68-74.

11. Teoh AY, Yan Chiu PW, Wong TC, Liu SY, Hung Wong SK, Ng EK. Functional performance and quality of life in patients with squamous esophageal carcinoma receiving surgery or chemoradiation: results from a randomized trial. Ann Surg. 2011;253:1-5.

12. Reynolds JV, McLaughlin R, Moore J, Rowley S, Ravi N, Byrne PJ. Prospective evaluation of quality of life in patients with localized oesophageal cancer treated by multimodality therapy or surgery alone. Br J Surg. 2006;93:1084-90.

13. Tatematsu N, Hasegawa S, Tanaka E, Sakai Y, Tsuboyama T. Impact of oesophagectomy on physical fitness and health-related quality of life in patients with oesophageal cancer. Eur J Cancer Care (Engl). 2013;22:308-13.

14. Aaronson NK, Ahmedzai S, Bergman B, Bullinger M, Cull A, Duez NJ, et al. The European Organization for Research and Treatment of Cancer QLQ-C30: a quality-of-life instrument for use in international clinical trials in oncology. J Natl Cancer Inst. 1993;85:365-76.

15. Blazeby JM, Alderson D, Winstone K, Steyn R, Hammerlid E, Arraras J, et al. Development of an EORTC questionnaire module to be used in quality of life assessment for patients with oesophageal cancer. The EORTC Quality of Life Study Group. Eur J Cancer. 1996;32A:1912-7.

16. Clifton JC, Finley RJ, Gelfand G, Graham AJ, Inculet R, Malthaner R, et al. Development and validation of a disease-specific quality of life questionnaire (EQOL) for potentially curable patients with carcinoma of the esophagus. Dis Esophagus. 2007;20:191-201.

17. Spruit MA, Singh SJ, Garvey C, ZuWallack R, Nici L, Rochester C, et al. An official American Thoracic Society/European Respiratory Society statement: key concepts and advances in pulmonary rehabilitation. Am J Respir Crit Care Med. 2013;188:e13-64

18. Hellstadius Y, Lagergren J, Zylstra J, Gossage J, Davies A, Hultman CM, et al. Prevalence and predictors of anxiety and depression among esophageal cancer patients prior to surgery. Dis Esophagus. doi:10.1111/dote.12437.

19. Silver JK, Baima J, Mayer RS. Impairment-driven cancer rehabilitation: an essential component of quality care and survivorship. CA Cancer J Clin. 2013:63:295-317.

20. Dindo D, Demartines N, Clavien PA. Classification of surgical complications: a new proposal with evaluation in a cohort of 6336 patients and results of a survey. Ann Surg. 2004:240:205-13.

21. Japanese-Respiratory-Society. Guidelines of respiratory function testsspirometry, flow-volume curve, diffusion capacity of the lung. Nihon Kokyuki Gakkai Zasshi. 2004:42:1-56.

22. ATS. ATS statement: guidelines for the six-minute walk test. Am J Respir Crit Care Med. 2002;166:111-7.

23. Poulain M, Durand F, Palomba B, Ceugniet F, Desplan J, Varray A, et al. 6minute walk testing is more sensitive than maximal incremental cycle testing for detecting oxygen desaturation in patients with COPD. Chest. 2003;123:1401-7.

24. Zigmond AS, Snaith RP. The hospital anxiety and depression scale. Acta Psychiatr Scand. 1983:67:361-70.

25. Suzukamo Y, Fukuhara S, Green J, Kosinski M, Gandek B, Ware JE. Validation testing of a three-component model of Short Form-36 scores. J Clin Epidemiol. 2011;64:301-8.

26. Jones PW, Harding G, Berry P, Wiklund I, Chen WH, Kline LN. Development and first validation of the COPD Assessment Test. Eur Respir J. 2009;34:648-54.

27. Dodd JW, Hogg L, Nolan J, Jefford H, Grant A, Lord VM, et al. The COPD assessment test (CAT): response to pulmonary rehabilitation. A multicentre, prospective study. Thorax. 2011;66:425-9.

28. Redelmeier DA, Bayoumi AM, Goldstein RS, Guyatt GH. Interpreting small differences in functional status: the Six Minute Walk test in chronic lung disease patients. Am J Respir Crit Care Med. 1997;155:1278-82.

29. Miyazaki M, Nakamura H, Chubachi S, Sasaki M, Haraguchi M, Yoshida S, et al. Analysis of comorbid factors that increase the COPD assessment test scores. Respir Res. 2014;15:13.

30. Woodruff PG, Barr RG, Bleecker E, Christenson SA, Couper D, Curtis JL, et al. Clinical significance of symptoms in smokers with preserved pulmonary function. N Engl J Med. 2016;374:1811-21.

31. Brooks JA, Kesler KA, Johnson CS, Ciaccia D, Brown JW. Prospective analysis of quality of life after surgical resection for esophageal cancer: preliminary results. J Surg Oncol. 2002:81:185-94.

32. Djarv T, Lagergren J, Blazeby JM, Lagergren P. Long-term health-related quality of life following surgery for oesophageal cancer. Br J Surg. 2008;95:1121-6.

33. Law S, Wong KH, Kwok KF, Chu KM, Wong J. Predictive factors for postoperative pulmonary complications and mortality after esophagectomy for cancer. Ann Surg. 2004;240:791-800.

34. Ferguson MK, Durkin AE. Preoperative prediction of the risk of pulmonary complications after esophagectomy for cancer. J Thorac Cardiovasc Surg. 2002;123:661-9.

\section{Submit your next manuscript to BioMed Central and we will help you at every step:}

- We accept pre-submission inquiries

- Our selector tool helps you to find the most relevant journal

- We provide round the clock customer support

- Convenient online submission

- Thorough peer review

- Inclusion in PubMed and all major indexing services

- Maximum visibility for your research

Submit your manuscript at www.biomedcentral.com/submit
) Biomed Central 